\title{
Análise gráfica dos cartazes do Vestibular da UEL do período de 2003 a 2016
}

\author{
Visual analysis of UEL entrance exam's posters from 2003 to 2016
}

\author{
GARCIA, Fátima Regina \\ Universidade Estadual de Londrina - UEL I fatimagarcia.tpt@gmail.com
}

\begin{abstract}
Resumo
Este artigo apresenta uma análise da composição visual dos cartazes do vestibular da Universidade Estadual de Londrina. Considerou as peças desenvolvidas pelos alunos do curso de Design Gráfico da mesma instituição, com o objetivo de ressaltar a importância do conhecimento e domínio dos fundamentos básicos do Design para a construção de mensagens visuais e identificar elementos pregnantes para o fortalecimento da identidade visual da Universidade. Utilizou como diretriz os fundamentos do Design elencados por Lupton (2014). Buscou compreender a importância desta iniciativa para o desenvolvimento profissional e acadêmico dos participantes e registrar o acervo considerando sua devida

\section{Abstract}

This paper presents an analysis on the visual composition of Londrina State University entrance exam's posters. The study took into consideration the pieces designed by students of the institution in the Graphic Design course, aiming to highlight the importance of knowledge and mastery of Design fundamentals for the construction of visual messages and identifying pragnanz ${ }^{*}$ in order to strengthen the University brand. Design fundamentals listed by Lupton (2014) were used as a guideline. The study sought to understand the importance of this educational activity for the professional and academic development of participants, and to keep records of the activity, given the historical role in regional design.
\end{abstract} importância histórica para o design regional.

Palavras-chaves: cartaz, sintaxe visual, Design Gráfico, composição visual

${ }^{\star}$ Rich in significance or comprehension.

Key-words: poster, visual syntax, Graphic Design, visual composition 


\section{INTRODUC̣ÃO}

A Universidade Estadual de Londrina (UEL) foi criada por meio do Decreto no 18.110 de 28 de janeiro de 1970, pela junção de cinco faculdades em atividade desde a década de 1950 e reconhecida por meio do Decreto Federal no 69.324, de 07/10/1971. Deu início às atividades contabilizando treze cursos de graduação (CEZAR; MARCONDES, 2013).

Por diversas vezes reconhecida como uma das melhores universidades do país possui importância vital para a cidade de Londrina/PR, uma vez que sua atuação vai além do ensino superior em todos os níveis, contemplando a comunidade externa, por meio de órgãos suplementares voltados para as áreas de saúde, veterinária, assuntos jurídicos e socioeconômicos, comunicação, cultura, ensino fundamental e médio, além de laboratórios, hospital e museu.

A comunidade universitária (docentes, discentes e funcionários) contribui diretamente para o desenvolvimento econômico, social e cultural da região. A instituição se consolidou como um importante centro de ensino, pesquisa e extensão, atraindo anualmente milhares de estudantes de diversas regiões do país, que buscam ingressar na Universidade por meio do concurso vestibular.

Em 1997 a UEL dá início ao Bacharelado em Desenho Industrial. Em 2005 o curso tem sua grade curricular reestruturada e passa a ser denominado Bacharelado em Design Gráfico por meio da Resolução CEPE n. 98, de 18.08.04.

Desde 2003 os alunos matriculados no terceiro ano do curso de Design Gráfico desenvolvem propostas para o cartaz de divulgação do concurso vestibular, objeto de estudo deste artigo. A atividade integra as disciplinas voltadas à produção e análise da imagem, possui caráter interdisciplinar e visa oportunizar o desenvolvimento profissional e acadêmico dos participantes por meio do atendimento de uma demanda real e importante para a instituição.

As propostas são apresentadas aos representantes da COPS Coordenadoria de Processos Seletivos - e a um público formado por professores e alunos do Departamento de Design, além de alunos secundaristas do Colégio Aplicação da UEL. Na ocasião, os grupos têm a oportunidade de apresentar o conceito e o processo criativo de cada proposta e o público, por meio de votação, escolhe a peça que será veiculada.

\section{METODOLOGIA}

O objetivo deste estudo é analisar a composição visual dos cartazes produzidos no período de 2003 a 2016 sob o ponto de vista dos fundamentos de composição e sintaxe visual no Design Gráfico apresentados por Lupton e Phillips (2014) no livro "Novos Fundamentos do Design". A obra foi escolhida 
por abordar o tema de forma oxigenada, incluindo novas possibilidades de produção da imagem, cada vez mais convergentes com o atual dinamismo tecnológico. A autora também considera em seus exemplos as mais variadas combinações de linguagem em manifestações visuais oriundas do 'hibridismo' entre o impresso, o vídeo e o digital.

Considerando que o aluno está inserido em uma sociedade cada vez mais permeada pela visualidade, e que no âmbito da faculdade ingressa dominando cada vez mais o digital, incluindo softwares de produção e edição de imagens, se faz necessário dar a devida atenção aos fundamentos básicos entendendo as ferramentas digitais como um meio e não um fim para a construção de uma mensagem visual, conforme sugere Lupton e Phillips (2014, p. 10):

\footnotetext{
Muitas vezes, a tentação de recorrer ao computador impede níveis mais profundos de pesquisa e pensamento - esta zona de destilação que ultrapassa o apetite mediano para testar novos terrenos e explorar alternativas. [...] Chegar a territórios mais interessantes requer a persistência de selecionar, organizar e assimilar temas e soluções até que uma nova fagulha surja e se sobressaia..
}

Os fundamentos considerados para construção da análise foram: ponto, linha, plano, ritmo, equilíbrio, simetria, assimetria, escala, textura, cor, figura/ fundo, enquadramento, hierarquia, tipografia, camadas, transparência, modularidade, grid, padronagem, diagrama, tempo, movimento, regras e acaso.

Cada cartaz foi analisado isoladamente, com o objetivo de identificar a presença ou ausência dos fundamentos citados acima. Para melhor guiar o estudo, cada fundamento foi avaliado em uma escala de zero a quatro, sendo zero a ausência total e quatro a utilização do fundamento como principal aporte para a construção da composição visual. Foram considerados para efeito de análise apenas os fundamentos que obtiveram pontuação máxima. Durante o processo, verificou-se que um mesmo cartaz pode ter mais de um fundamento predominante.

Sendo o cartaz uma mídia capaz de fortalecer e/ou disseminar a identidade visual daquilo que promove, conceito este que será abordado no decorrer do artigo, identificou-se a necessidade de utilizar como complemento para análise de algumas peças do acervo os conhecimentos básicos de semiótica fundamentados por Santaella, em seus livros "O que é Semiótica" (1983) e "Semiótica Aplicada" (2005). A semiótica será utilizada como aporte para a compreensão da eficácia da comunicação entre interlocutor e receptor, abarcando alguns signos incorporados à identidade da UEL e presentes na maioria dos cartazes.

\section{CONCEITOS}

O cartaz e o Design Gráfico 
O pôster, ou cartaz, está intrinsecamente ligado à vida urbana, e no fim do século XIX surge como uma forma de expressão da vida social, política, econômica, artística e cultural, com o objetivo de atrair o olhar dos transeuntes para a mensagem divulgada. Para Hollis (2000, p. 5), "o pôster, como design gráfico, pertence à categoria da apresentação e da promoção, na qual imagem e palavra precisam ser econômicas e estar vinculadas a um significado único e fácil de ser lembrado".

O cartaz ao longo da história passou por diversas transformações, sempre influenciado pelo momento histórico, social e tecnológico no qual está inserido, sendo um espelho destes. Sua ubiquidade o transformou em um poderoso instrumento de comunicação "[...] pela sua repetição em múltiplas cópias postas em diferentes lugares, o cartaz se decalca, pouco a pouco no cérebro dos membros da sociedade para aí se constituir num elemento da cultura". (MOLES, 1974, p. 27).

Inicialmente a produção de cartazes estava condicionada aos meios de produção, principalmente tipográficos e ilustrações xilográficas, em preto e branco. Os avanços tecnológicos permitiram maiores possibilidades compositivas. A invenção da litografia (do grego "impressão por pedra") em 1796, por Aloys Senefelder, foi um dos fatores principais para o crescimento e a expansão deste tipo de mídia, ao permitir impressão em grandes formatos e cores.

Na metade do século XIX, o cartaz e a folha impressos tipograficamente encontravam a concorrência de um cartaz mais figurativo e sedutor. A litografia era o meio gráfico que possibilitava uma abordagem mais ilustrativa da comunicação pública. (MEGGS; PURVIS, 2009, p. 204).

O artista gráfico francês Jules Chéret (1836-1933), filho de tipógrafo e aprendiz de litógrafo difundiu as possibilidades da litografia. Foi um dos grandes precursores do movimento Arts and Crafts, e da difusão do cartaz como uma importante peça de comunicação no meio urbano. Henri de ToulouseLautrec (1864-1901) foi outro importante artista francês que contribuiu para a sofisticação da linguagem dos cartazes. Suas criações ampliaram as possibilidades compositivas e simbólicas e a relação entre imagem e texto.

O cartaz contribuiu para o desenvolvimento da comunicação visual uma vez que esta mídia serve à cultura, à sociedade, à politica e à publicidade, e, para ser notado, um cartaz precisa se claro e transmitir uma mensagem pregnante, informativa e legível. Moles (1974) classifica seis funções para um cartaz: informação, propaganda e publicidade, educadora, ambiência, estética e criadora.

Destacam-se duas funções: informação e estética. A função de informação “[...] tal produto a tal preço, vendido em tal lugar; é o anuncio, o cartaz anunciador, 
no qual o papel semântico é essencial" (MOLES, 1974, p. 53). A função estética refere-se à sugestão. Está ligada à mensagem conotativa, à poesia.

\begin{abstract}
A grande regra de todas as regras para comunicar é a de agradar e agradar significa, entre outras coisas, ter um valor estético, ultrapassar a significação, criar, ao redor desta, um campo estético explorado pelo artista. O jogo das cores e das formas, o jogo das palavras e das imagens, o contraste e a suavidade, são fatores onde se exerce sua função artística. Um cartaz pode, pela beleza, desempenhar, em relação à massa social um outro papel além daquilo que ele tem a dizer. O indivíduo pode recusar o seu sentido e aceitar o seu valor, o cartaz enfeita a cidade ou a enfeia, mas, por isso mesmo, a faz sair do estrito campo semântico. (MOLES, 1974, p.55-56).
\end{abstract}

O cartaz perpetuou-se durante mais de um século como o principal veículo de comunicação para as massas. Permitiu a convergência de técnicas e contribuiu para o desenvolvimento do design gráfico contemporâneo, uma vez que não apenas promove um determinado evento ou produto, mas se torna parte da identidade visual do mesmo. Trata-se ainda de um artefato histórico, uma vez que é um produto de seu tempo, refletindo a sociedade e a cultura da qual faz parte.

\title{
ANÁLISE GRÁFICA
}

Figura 1- Cartazes do Vestibular da UEL de 2003 e 2004

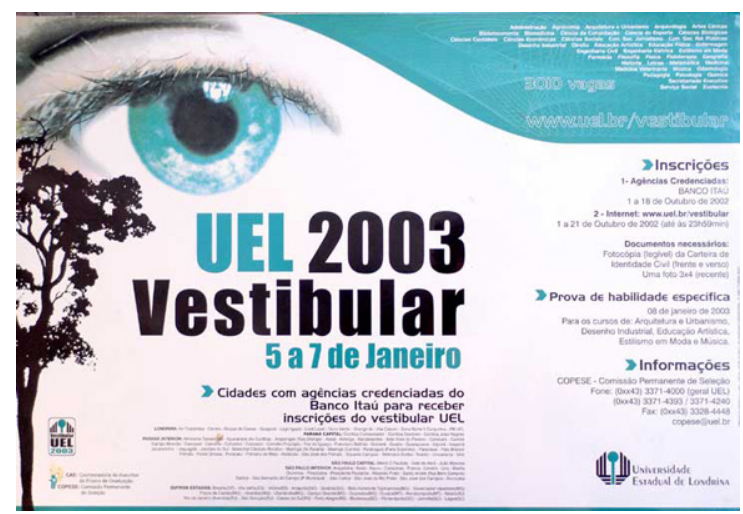




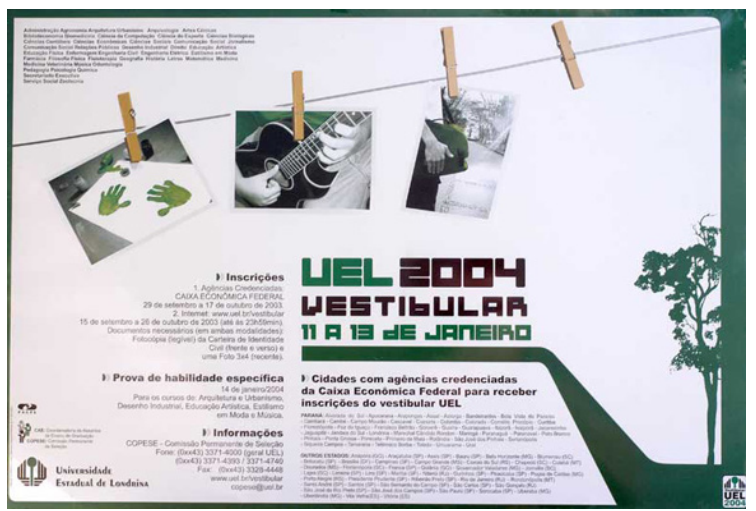

Fonte: UEL (2015)

O cartaz de 2003 foi o primeiro desenvolvido pelos alunos de Design Gráfico, por meio de um processo de criação coletivo em que todos do grupo participaram.

O apuramento gráfico é percebido na ordenação dos elementos em um grid bem definido. Este é um dos grandes diferenciais percebidos para a organização das informações. "Um grid bem feito incentiva o designer a variar a escala e o posicionamento dos elementos, sem precisar contar apenas com julgamentos arbitrários e caprichosos" (LUPTON; PHILLIPS, 2014, p.174). A imagem de um olho humano ocupa o primeiro terço superior do cartaz em escala aumentada. Junto a este somam o título e a peroba-rosa. Por sua importância e poder de atração, estes elementos estão estrategicamente dispostos com o objetivo de direcionar o olhar do observador para as informações mais importantes. Utiliza apenas as cores presentes na marca UEL: verde, branco e preto.

Esta peça possui uma extensa quantidade de textos com informações complementares e secundárias e para que este conteúdo seja consumido é necessário que o observador se aproxime e disponha de um tempo para leitura. Apesar de desaconselhável para um cartaz, a massa de textos está organizada hierarquicamente por meio de tamanhos, estilos tipográficos, blocos de textos, alinhamento e entrelinhas, o que permite acessar rapidamente os conteúdos mais importantes.

Uma hierarquia tipográfica indica um sistema que organiza conteúdo, enfatizando alguns dados e preterindo outros. A hierarquia ajuda os leitores a localizarem-se no texto, sabendo onde entrar e sair e como selecionar algumas de suas ofertas. Cada nível deve ser indicado por um ou mais sinais aplicados consistentemente ao longo do texto. (LUPTON, 2013, p.128).

O projeto como um todo reflete uma preocupação com a ordenação do conteúdo em uma estrutura capaz de comunicar de forma eficaz. 
Em 2004 a turma foi dividida em grupos, sendo que cada grupo apresentaria uma proposta a ser escolhida pela COPS. O cartaz escolhido foi criado pelos alunos Maikon Nery, Gulherme Baracat, Yam Sorgi e Henrique lamarino Farto Pereira. $\mathrm{O}$ cartaz produzido recebe influências da peça anterior. $\mathrm{O}$ grid é semelhante e a distribuição das informações no espaço segue uma hierarquia parecida. Além dos elementos como a peroba e o logotipo da UEL, é possível observar uma continuidade no que se refere à utilização das cores institucionais (verde, branco e preto), com predominância do verde como principal informação de marca. A cor possui forte influência na percepção humana e pode ser uma poderosa ferramenta na construção de identidades visuais fortes. Wheller (2012, p. 138) exemplifica esta importância:

\begin{abstract}
A cor é utilizada para evocar emoções e expressar personalidades. Ela estimula a associação da marca e acelera a diferenciação. Como consumidores, dependemos de nossa familiaridade com o vermelho da Coca-Cola. Não precisamos ler a tipografia da caixa de presentes da Tiffany para saber onde o presente foi comprado. Vemos a cor e sentimos imediatamente uma série de impressões.
\end{abstract}

Além da utilização das cores institucionais, a utilização de um grid hierárquico permite ao observador acessar os conteúdos ordenadamente. As fotos penduradas no varal remetem a atividades desenvolvidas no meio acadêmico, sendo parte da retórica do cartaz.

Figura 2- Cartaz do Vestibular da UEL de 2005 e 2006

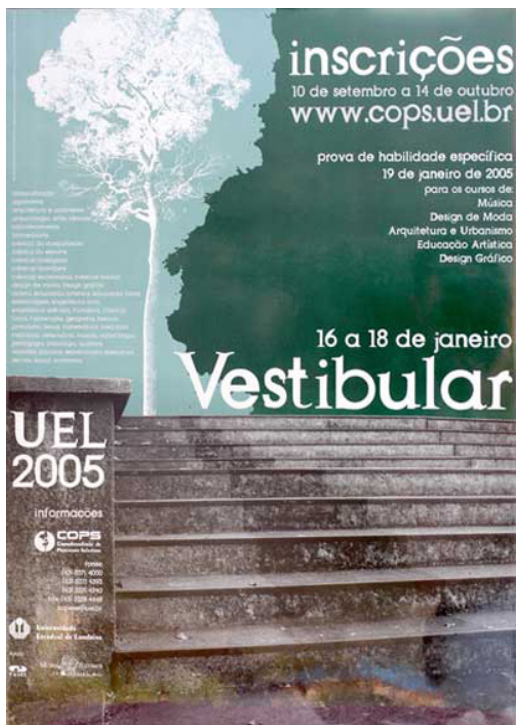




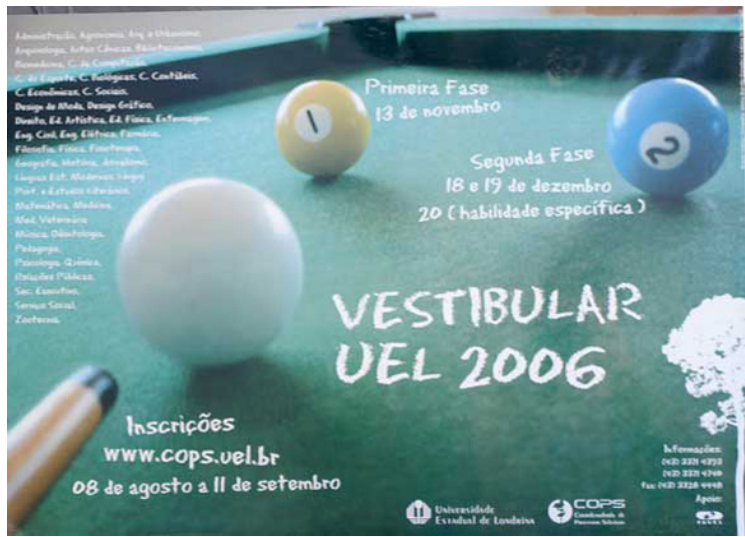

Fonte: UEL (2015)

Em 2005, os autores Diogo Blanco, Juliana Brandão Dornelles, Carlos Pereira e Sabrina Traldi utilizam a imagem da peroba-rosa pela terceira vez consecutiva. Anteriormente utilizada discretamente, nessa criação a árvore ganha destaque e se torna o assunto do cartaz. O campus universitário tem como característica a ampla arborização, e, no passado, possuía diversos exemplares centenários desta espécie de árvore. A constante utilização deste elemento gráfico pode ser justificada como uma informação da marca:

A marca-símbolo da Universidade Estadual de Londrina foi instituída pela Resolução n 276/75 de 5 de julho de 1975, cujo significado corresponde ao trinômio das funções da Universidade: o Ensino, a Pesquisa e a Extensão, representado pelas três faixas que desenham o " $U$ " de Universidade. A circunferência central e a haste que a sustenta, simbolizam a peroba, árvore original do Campus onde está instalada a Universidade. (UEL, 2016).

O cartaz utiliza predominantemente a textura e o contraste entre figura e fundo. Os espaços positivos e negativos revelam a silhueta da peroba em dois planos, em que o contraste de cor entre tons de verde revela a copa da peroba e a árvore integral em planos distintos. Segundo Lupton e Phillips (2014), os designers utilizam a relação figura/fundo com o objetivo de proporcionar energia e ordem à forma e ao espaço, criando contrastes entre forma e contra forma, com o objetivo de estimular o olhar. Importante salientar que segundo Gomes Filho (2009) a Gestalt, campo que estuda a psicologia perceptual da forma, oferece subsídios para representar um objeto em consonância com a maneira com que o cérebro humano compreende e/ou interpreta um determinado estímulo visual. Figura e fundo podem ser interpretados por meio da capacidade de organização da forma, sendo figura aquilo para o qual se volta o interesse.

Quanto à textura, o observador pode notar a rusticidade do concreto na imagem da escadaria, fotografada em ângulo contra-plongeé. A sensação de textura pode ser experimentada de forma tátil, por meio dos mais diversos 
tipos de materiais e acabamentos gráficos, ou, como no caso da peça analisada, visualmente.

\begin{abstract}
Muitas das texturas que os designers manipulam não são de maneira alguma experimentáveis fisicamente pelo observador, pois só existem como efeito ótico, como representação. A textura acrescenta detalhes a uma imagem, proporcionando mais qualidade à superfície como um todo e recompensando o olhar daquele que a observa. (LUPTON; PHILLIPS, 2014, p.53).
\end{abstract}

A textura é capaz de evocar sentimentos e sensações, uma vez que na natureza ela nos ajuda a compreender o ambiente. Além da escada, é possível observar a textura na ilustração da peroba-rosa.

Os três primeiros cartazes produzidos até então se assemelham por enfatizar a universidade por meio da representação de elementos próprios da paisagem do campus e de ações características do ambiente universitário. Em 2006 a UEL adota um novo modelo de aplicação do concurso vestibular. Anteriormente aplicadas em uma única fase, as provas passam a ser divididas em duas etapas, sendo a primeira sobre conteúdos gerais e a segunda, após um mês, sobre português, língua estrangeira e conhecimentos específicos.

Este exemplar, criado por Juliana Brandão Dornelles e Sabrina Traldi inova ao utilizar a metáfora visual como meio de transmissão da mensagem. Segundo Bertomeu (2006, p. 40), "metáfora é o desvio da significação própria de uma palavra, nascida de uma comparação mental ou característica comum entre dois seres ou fatos." Segundo Santaella (2005), a metáfora seria para Pierce, juntamente com a imagem e o diagrama, um dos três níveis de signos icônicos, ou seja, signos que agem em função de uma relação de semelhança com seus objetos.

\footnotetext{
A metáfora representa seu objeto por similaridade no significado do representante e do representado. Ao aproximar o significado de duas coisas distintas, a metáfora produz uma faísca de sentido que nasce de uma identidade posta à mostra. É justamente esse efeito que uma frase do tipo "Ela tem olhos de azeitona" produz. (SANTAELLA, 2005, p18).
}

A utilização do jogo de sinuca cria uma relação de comparação e proximidade entre as duas situações, uma vez que o vestibulando (jogador) precisa passar na primeira fase para prosseguir no concurso. O cuidado com os detalhes, como a escolha da tipografia que imita a escrita em giz, característica própria deste tipo de jogo e do ambiente escolar, auxilia no sucesso da comunicação. A utilização do enquadramento e do recorte proporciona ao cartaz dinamismo e movimento, permitindo ao observador se sentir parte da 
ação. Segundo Lupton e Phillips (2014) recortando uma fotografia ou ilustração o designer redesenha seus limites e altera sua forma ao mudar a escala de seus elementos em relação à totalidade da imagem.

Este cartaz inova uma vez que se desprende do uso da peroba e de imagens do campus, inserindo outros elementos para construção da mensagem. Tem como principal informação de marca a utilização da cor verde.

Figura 3- Cartazes do Vestibular da UEL de 2007 e 2008

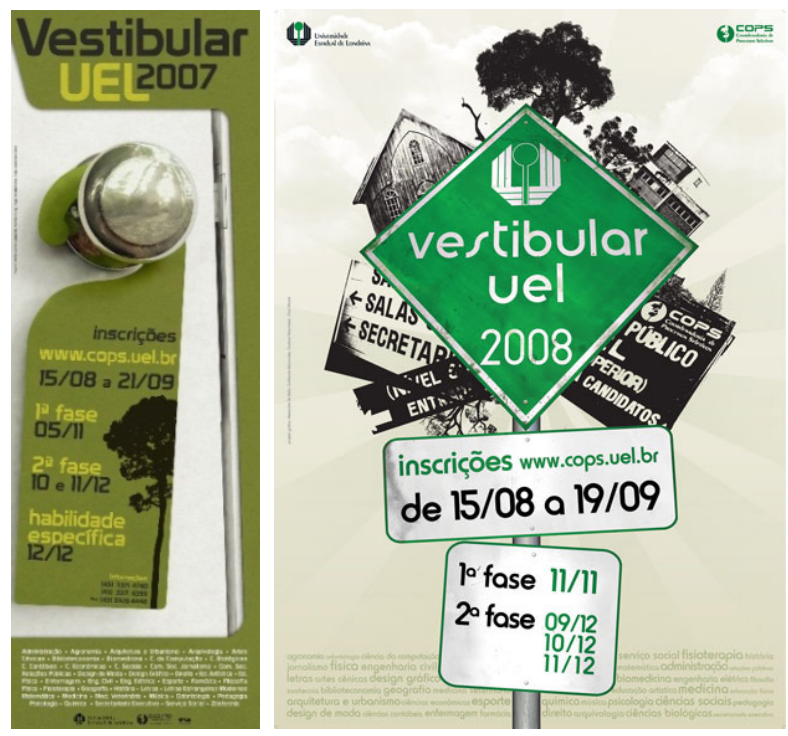

Fonte: UEL (2015)

O cartaz de 2007, criado por Leonardo Chung, Livia Lopes Santanna e Felipe Malasisse explora um formato diferenciado, mais estreito e mais alto que os demais. Na imagem, uma placa igual às utilizadas com a mensagem "não perturbe" está pendurada na maçaneta de uma porta. Nela estão contidas as informações sobre as datas de realização das provas, o endereço eletrônico para inscrição no concurso e os telefones para contato.

Esta mesma placa foi produzida e distribuída como material gráfico promocional com o objetivo de gerar interatividade e identificação junto ao público alvo, podendo ser utilizada assim como se propõe na imagem do cartaz, indiciando que naquele momento o candidato está ocupado estudando para o concurso. Em semiótica, o índice "é um signo que como tal funciona porque indica outra coisa com a qual ele está factualmente ligado". (SANTAELLA, 1983, p. 66).

A filipeta e a maçaneta ganham destaque na peça visto à utilização do enquadramento e do recorte. "O enquadramento faz parte da arquitetura fundamental do design gráfico. [...] ele é um dos atos mais persistentes, inevitáveis e infinitamente variáveis efetuados pelo designer", (LUPTON; PHILLIPS, 2014, p.100).

O cartaz de 2008, criado por Alexandre de Bellis, Guilherme Marcondes e Gustavo Nascimben possui ritmo e equilíbrio. Uma placa ocupa posição central 
na peça vertical e a informação "Vestibular UEL 2008" é o principal ponto focal, destacado também pela cor verde em um cartaz com fundo predominantemente preto e cinza. O ser humano busca naturalmente o equilíbrio, sendo este parte vital para a sobrevivência. Graficamente, o projeto é equilibrado, porém assimétrico.

\begin{abstract}
[...] a simetria não é o único meio de atingir o equilíbrio. Projetos assimétricos são geralmente mais ativos que os simétricos; e os designers atingem o equilíbrio ao colocar elementos contrastantes em contraponto um com o outro, produzindo composições que permitem ao olho perambular dentro de uma estabilidade geral. (LUPTON; PHILLIPS, 2014, p.30).
\end{abstract}

Tendo como base um objeto central, outros elementos ganham profusão e dinamismo. Estes elementos fazem parte do campus, sendo estes placas de sinalização, departamentos, a capela da UEL - réplica da primeira catedral da cidade de Londrina - além da peroba-rosa.

Figura 4- Cartazes do Vestibular da UEL de 2009 e 2010

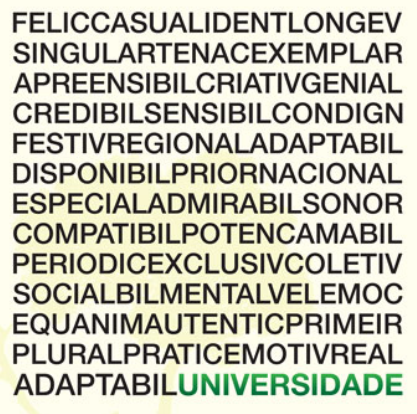

VESTIBULARUEL2009

INSCRIÇÕES:de13/08a17/09/2008

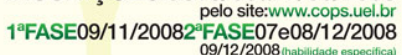
$0.6 \mathrm{coms} \quad 09 / 12 / 2008$ (nablidade ospecifica)

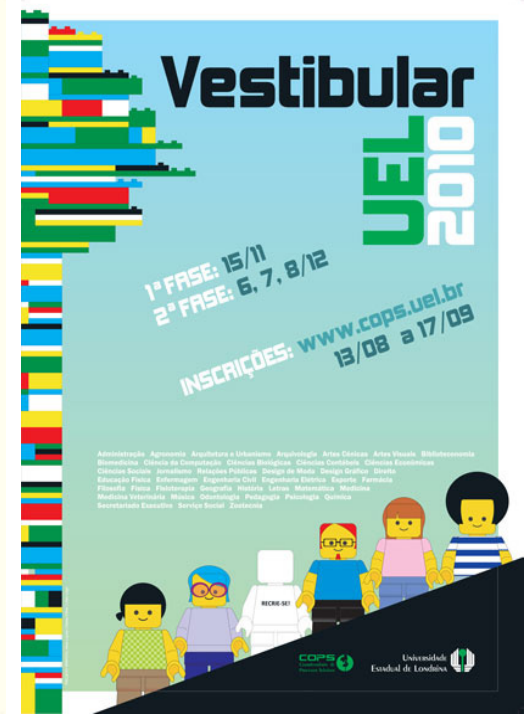

Fonte: UEL (2015)

O cartaz de 2009, criado por Marcos Almeida, se difere dos demais pelo uso da tipografia como protagonista da composição. A parte superior é composta por uma caixa de textos sólida, com tipos em caixa-alta que rimam com universidade por meio do sufixo "-dade" ("-idade"). Alguns exemplos são sensibilidade, adaptabilidade, disponibilidade, criatividade, entre outras. Apenas a palavra universidade está completa. As demais têm seu sufixo suprimido e são completadas mentalmente por meio da semelhança estrutural entre elas.

Enquanto cartaz tipográfico se faz necessário algumas considerações sobre a parte inferior, local em que estão todas as informações úteis sobre o concurso. Com o objetivo de seguir a estética da parte superior do cartaz, 
optou-se pela supressão do espaço entre palavras, decisão esta que prejudica a legibilidade das informações por sufocar o texto; prejuízo este minimizado apenas pela separação de algumas palavras por cor.

\begin{abstract}
A legibilidade das letras tipográficas não depende apenas de sua forma ou da tinta que as imprime, mas também dos espaços vazio esculpido entre elas e à sua volta. Quando o tipo é moldado e composto à mão, esse espaço é definido fisicamente por blocos de metal. Quando ele é reduzido a um desenho armazenado em formato digital ou fotográfico, continua a possuir um espaço próprio, definido pela altura e pela largura nominais de seu corpo. (BRINGHHURST, 2015, p.43).
\end{abstract}

O excesso de proximidade entre linhas das quatro informações que sucedem o título "Vestibular UEL 2009" torna a leitura confusa e cansativa. "Tipos mais pesados precisam de entrelinhas maiores do que tipos mais leves. Tipos de corpo grande pedem uma entrelinha maior do que tipos de corpo pequeno". (BRINGHURST, 2015, p. 45).

A tipografia pode ser usada de duas formas: enquanto conceito, desprendida de regras e desnuda de sua função prática, servindo a um propósito conceitual e ilustrativo como no caso do bloco superior; ou servindo ao texto, com o objetivo de comunicar uma determinada informação. A composição, neste caso, pode considerar estas duas variações, sem prejuízo do valor estético e simbólico.

Em 2010, o cartaz criado por Gisele Erthal, Lilian Lago e Aline Loyola faz uma referência explicita ao brinquedo de montar da marca Lego. Utiliza ilustração vetorial para representar a peroba-rosa e os alunos. Um dos bonecos está em branco, sugerindo um espaço reservado para o novo calouro. Utiliza a modularidade como assunto principal. Segundo Lupton e Phillips (2014), o módulo é um elemento fixo utilizado no interior de uma estrutura maior. Trabalhar com padrões não significa monotonia ou limitação, uma vez que todo projeto possui uma série de restrições.

\footnotetext{
Um grid de nove por nove pixels pode produzir um número infinito de tipos diferentes. Do mesmo modo, uma pequena quantidade de peças de LEGO contém um número assustador de combinações possíveis. A variedade ilimitada de formas ocorre, no entanto, dentro dos parâmetros estritos do sistema, que permite apenas um tipo básico de conexão. (LUPTON; PHILLIPS, 2014, p.59).
}

Se comparada às peças anteriores, este exemplar quebra alguns padrões e sugere uma abordagem mais livre, uma vez que escolhe trabalhar com uma ilustração que remete ao universo lúdico dos brinquedos e cores predominantemente primárias e secundárias. 
Figura 5- Cartazes do Vestibular da UEL de 2011 e 2012
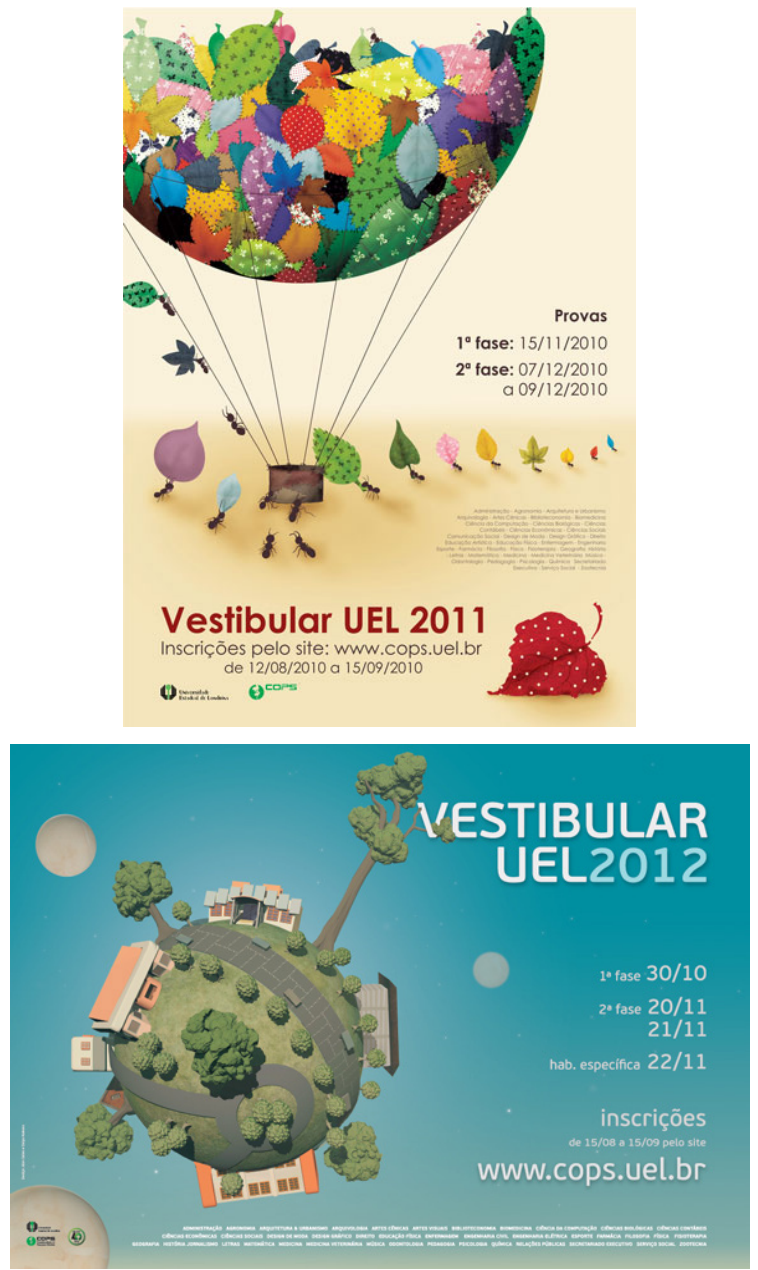

Fonte: UEL (2015)

O cartaz de 2011, criado por Janaina Oliveira e Cátia Germani recebe influências do cartaz de 2010: possui caráter lúdico e utiliza uma ampla paleta de cores. A peroba cede lugar a folhas que juntas se transformam em um balão, e a mensagem de construção por meio de esforços individuais e do trabalho em equipe, representado pela ação das formigas fica evidente. A padronagem é a protagonista da peça, referenciando o artesanato e o patchwork. Segundo Lupton e Phillips (2014) os designers modernos do século XX evitaram o uso de ornamentações em favor de uma estética mais limpa e simples. O retorno dos ornamentos "[...] está ligado à volta do artesanato na arquitetura, nos interiores e produtos $[. .]$.$" .$

Trata-se de uma composição harmônica e delicada, pela textura das folhas, pelo uso de padrões em Poá, folhas com textura de tecido, cores variadas e fundo sépia. Possui unidade, harmonia e liberdade criativa. Não utiliza elementos que ofereçam alguma ligação com os cartazes anteriores, com exceção da assinatura com os logotipos da UEL e da COPS.

No ano de 2012 a UEL completou 40 anos, e o cartaz do vestibular deste mesmo ano, criado por Alan Sales e Daiya Nakano retoma a utilização do campus e sua arquitetura como figura principal de forma lúdica: por meio 
de ilustração digital 3D o campus universitário se transforma em um planeta orbitando um céu limpo e azul.

Uma ilustração tridimensional só é possível se o designer considerar espaço e volume, representados visualmente por meio da perspectiva ótica, uma vez que esta é gerada para ocupar uma superfície bidimensional, no caso o papel. Segundo Lupton e Phillips (2014), uma folha de papel ou tela de computador não tem profundidade real, logo o volume é representado por meio de convenções gráficas.

A composição possui respiro visual e a disposição dos elementos gráficos no espaço permite uma leitura visual clara e objetiva. O observador possui dois pontos focais importantes: o planeta e as informações textuais.

Figura 6- Cartazes do Vestibular da UEL de 2013 e 2014

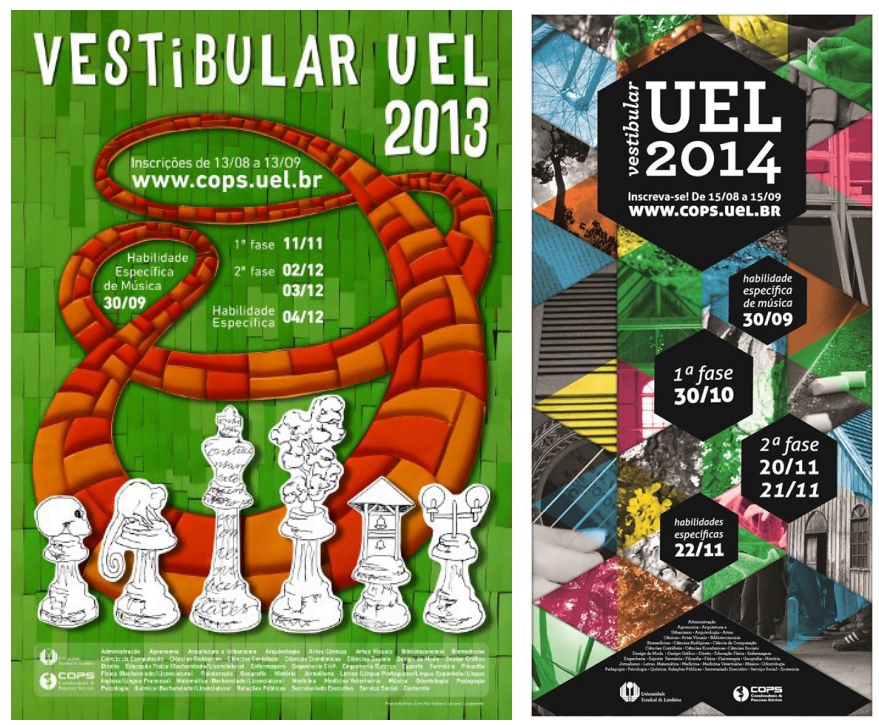

Fonte: UEL (2015)

O cartaz de 2013, criado por Aline Mie Nakae e Lariane Casagrande tem uma proposta visual ousada: por meio de ilustração manual e digital, colagem e fotografia representa alguns elementos arquitetônicos e naturais do campus universitário em formato de peças de um jogo de xadrez, em que o calçadão do campus se assemelha a um tabuleiro e a um caminho a ser percorrido. Enquanto proposta estética utiliza principalmente camadas: sobreposto um a um, todos os elementos estão colados, e as peças do jogo de xadrez, em preto e branco, ganham destaque por estarem em um fundo colorido.

Atualmente o conceito de camadas está presente nos principais softwares de edição gráfica e musical, e, segundo Lupton e Phillips (2014) antes dos anos 1990 os designers criavam "artes finais" compostas, precisamente, de camadas alinhadas de papel e acetato. Vista sob a perspectiva da mensagem e considerando seu poder de comunicação, a utilização de elementos como a lâmpada do campus, o sino da capela e o macaco restringe a mensagem simbólica ao público universitário e àqueles que porventura conhecem o campus, para 
os quais estes detalhes possuem um significado. Aos demais, é passível outras interpretações, que irão adquirir sentido com base em outro repertório.

\begin{abstract}
Em síntese: compreender, interpretar, é traduzir um pensamento em outro pensamento num movimento ininterrupto, pois só podemos pensar um pensamento em outro pensamento. É porque o signo está numa relação a três termos que sua ação pode ser bilateral: de um lado, representa o que está fora dele, seu objeto, e de outro lado dirige-se para alguém em cuja mente se processará sua remessa para um [outro] signo ou pensamento onde seu sentido se traduz. (SANTAELLA, 1983, p. 52).
\end{abstract}

O caráter experimental da peça confere ao cartaz um tom mais livre. Isolando sua mensagem e seu poder de pregnância, esta corre o risco de se dissolver em outros significados que não os determinados por seus criadores, enfraquecendo a comunicação.

A partir de 2013 a COPS passa a divulgar no Manual do Candidato um texto explicativo que discorre sobre o conceito do cartaz. Segundo o Manual de 2014, o tema para o cartaz do mesmo ano foi "Explore seu futuro". Os autores Murilo Crivellari Camargo, Gabriel Darcin Alsouza e Marília Pinotti entrevistaram 185 jovens do terceiro ano do Ensino Médio e de cursinhos preparatórios - sendo uma instituição de ensino público e outra de ensino privado - na cidade de Londrina, no Paraná, perguntando a eles o que significa ingressar na UEL. Três respostas se destacaram e foram utilizadas para a construção do cartaz, inspirado nas palavras futuro, crescimento pessoal e profissional e oportunidade.

A composição visual correlaciona transparência e camada. Detalhes de fotos em preto e branco do campus universitário são combinadas e sobrepostas por triângulos coloridos, gerando o que, segundo Lupton e Phillips (2014), pode ser denominado como "transparência gráfica", em que duas ou mais imagens sobrepostas são visíveis em uma mesma superfície. Os triângulos formam hexágonos que se repetem ao longo da peça, em um grid modular. No caso desta peça, as fotos não se misturam por meio da transparência digital, pois as formas geométricas criam linhas bem definidas que separam as imagens. 
Figura 7- Cartazes do Vestibular da UEL de 2015 e 2016

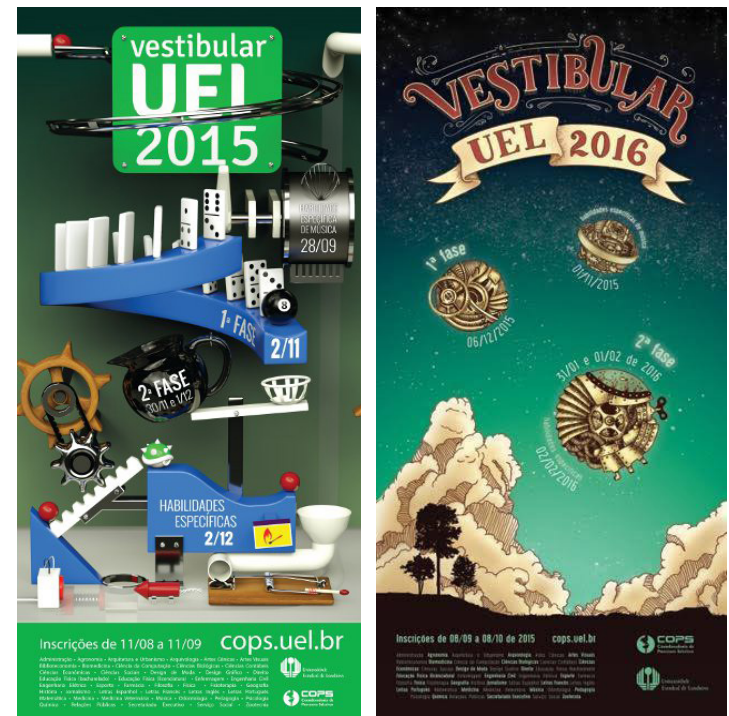

Fonte: UEL (2015)

O cartaz de 2015, criado por José Vicentin, Pedro Lot e Felipe Rostirolla prende a atenção: por meio de ilustração tridimensional, uma complexa engrenagem "brinca" com o olhar do observador que pode imaginar o movimento implícito na imagem e seus potenciais desdobramentos. O inicio se dá no canto superior esquerdo do cartaz: uma esfera vermelha, quando lançada, escorrega por uma tubulação e dá inicio a uma série de ações que são concluídas no canto inferior esquerdo. Cada ponto crítico representa uma fase do vestibular com a respectiva data da prova.

Utiliza o diagrama, presente nos infográficos em geral, permitindo descrever situações, processos, estruturas, fatos históricos, processos e ideias. Os diagramas [...] "nos permitem enxergar relações que não viriam à tona numa lista convencional de número, nem numa descrição verbal". (LUPTON; PHILLIPS, 2014, p. 199). Os infográficos, prioritariamente utilizados no design de informação, utilizam as relações visuais, podendo ser estas figurativas ou abstratas, codificando-as para criar um significado e transmitir uma informação.

No caso do cartaz, cada elemento isolado possui um significado. Juntos, mas sem a relação com o título e demais textos, não transmitem uma real compreensão da mensagem, visto que os textos são os únicos elementos que fazem referência explicita à UEL.

O diagrama representa seu objeto por similaridade entre as relações internas que o signo exibe e as relações internas do objeto que o signo visa representar. O mapa do metrô de Londres, por exemplo, é um diagrama, pois a similaridade com seu objeto não se dá no nível das aparências, mas no nível das relações internas. O gráfico demonstrando a taxa de crescimento da inflação no ano também é um diagrama por exibir uma correspondência do desenho com 
as relações internas do objeto representado. (SANTAELLA, 2005, p.18).

Em 2016 a busca pelo tema extrapolou os limites da universidade e invadiu o mundo dos livros. Segundo declaração dos autores Karoline Tiemi Nakahara, Nicolas Lopes Pereira e Tatiana laquinto no Manual do Candidato de 2016, a temática foi inspirada no universo literário do escritor francês Jules Verne, em especial pelos livros "Viagem ao centro da Terra", "Vinte mil léguas submarinas" e "Raio verde", livros estes que trouxeram o estilo Steampunk ao projeto.

\begin{abstract}
Os steampunks exploram um suposto "mundo alternativo" movido a vapor (steam), cujas histórias se passam num tempo híbrido entre a Era Vitoriana e um futuro sob a ótica punk. Nesse ambiente, visualizam-se engrenagens, como grandes zepelins (símbolo da entrada da tecnologia também pelos céus afora) cruzando os ares comandados por piratas; roupas vitorianas que ganham uma aparência punk; máquinas antigas remodeladas pelas tecnologias atuais. (HERSCHMANN; PEGORARO; FERNANDES, 2013).
\end{abstract}

Por meio de ilustração manual, um universo fantástico que mistura o passado e o futuro tecnológico representa o papel da ciência no desenvolvimento humano. O estilo pode ser observado pela ilustração preferencialmente manual, pela escolha do lettering para o título e pela paleta de cores.

O cartaz convida a explorar, apesar de sua complexidade, os alicerces do design: o ponto, a linha e o plano. É a partir destes elementos que a complexidade se torna possível. O ponto pode ser observado no céu cravejado de estrelas e nas estruturas circulares e mecânicas que flutuam neste mesmo céu. "Através de sua imensidão, posição e relação com suas imediações, um ponto pode expressar sua própria identidade ou mesclar-se à massa". (LUPTON; PHILLIPS, 2014, p. 14). A linha, resultante de uma sequência infinita de pontos é a base para a construção de todo o desenho. Linhas retas representam a sombra em toda a ilustração. As linhas "[...] podem ser retas ou curvas, contínuas ou tracejadas. Quando uma linha atinge certa espessura torna-se um plano". (LUPTON; PHILLIPS, 2014, p. 16). Todas as formas representadas na peça estão condicionadas ao pleno conhecimento da importância dos fundamentos e ao domínio das técnicas de composição visual e ilustração. 


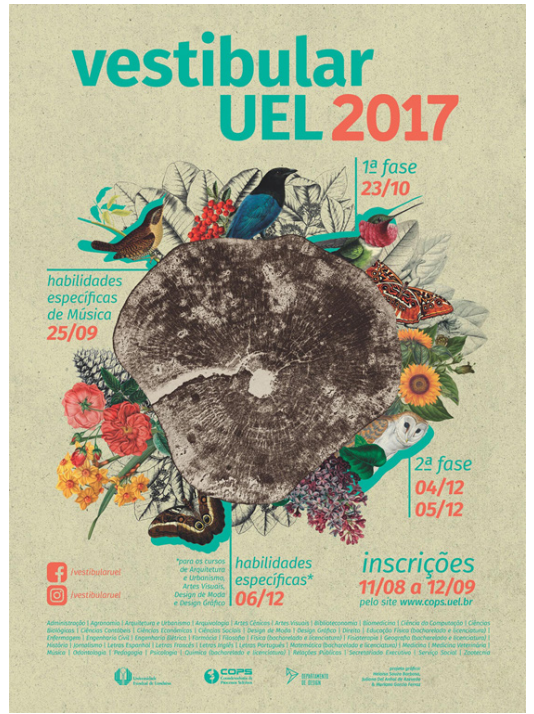

Fonte: UEL (2016a)

O cartaz de 2017, criado por Juliana Azevedo, Heloisa Barbosa e Marina Ferraz busca inspiração na fauna e flora paranaense, comum ao campus universitário. Segundo entrevista concedida pelas autoras ao portal de notícias da universidade (BOTELHO, 2016), o cartaz foi resultado de um extenso trabalho de pesquisa junto aos professores dos Departamentos de Biologia e Agronomia da mesma instituição, com o objetivo de elencar as diversas espécies de plantas e animais representativos da região.

A peroba-rosa é representada por meio da técnica de gravura de topo, em que o tronco da árvore é cortado no sentido transversal possibilitando a vista dos anéis na parte superior da superfície da madeira, pigmentado e gravado em papel. Carregada de forte apelo sensorial, a gravura evidencia a textura do objeto e resgata a xilogravura, antiga técnica de impressão de composições talhadas em madeira, entintadas e prensadas contra o papel. No caso do objeto analisado, a gravura retrata a anatomia natural da árvore, sem necessidade de qualquer intervenção por meio do entalhe.

As escolhas compositivas se assemelham ao cartaz de 2008 no que se refere à disposição dos elementos: o tronco da peroba é circundado por aves, insetos e plantas representados por meio de llustração científica assim como no cartaz de 2008 uma placa verde é circundada por ilustrações de elementos da arquitetura e da flora do campus. Guardadas as devidas diferenças entre os dois cartazes, a comparação entre eles se justifica pela utilização dos fundamentos visuais de ritmo e equilíbrio, tanto no que se refere à qualidade de ordenação dos elementos na página de forma coesa e harmônica, quanto à escolha por um objeto estático central em contraste a objetos dinâmicos em seu entorno. Conforme define Lupton e Phillips (2014, p. 29) 
relações entre elementos em uma página nos lembram as relações físicas. $O$ equilíbrio visual acontece quando o peso de uma ou mais coisas está distribuído igualmente ou proporcionalmente no espaço. [...] O equilíbrio e o ritmo trabalham juntos para criar designs que pulsem com vida, atingindo estabilidade e surpresa.

\section{RESULTADOS E DISCUSSÕES}

A análise dos cartazes desenvolvidos até o presente momento permite algumas constatações importantes. Pela acuidade visual das peças e pelo requinte gráfico se observa um significativo domínio dos fundamentos básicos do Design, permitindo composições complexas e poucas não conformidades. $O$ acervo é composto por artefatos que buscam uma determinada homogeneidade, porém ricos em pluralidade visual, uma vez que, mesmo sob orientação dos professores da academia, é desenvolvido por diversos autores que estão construindo seu repertório visual, mas que possuem característica e estilo pessoais.

Até 2009 é possível visualizar uma continuidade no que se refere à cor. Nota-se um esforço em consolidar o verde como cor institucional, fato positivo uma vez que a cor é amplamente utilizada em sistemas de identidade visual, e o cartaz, enquanto peça promocional tem o poder de imprimir na mente do público uma percepção sólida da marca. A partir de 2010 as criações são mais livres neste sentido, permitindo maior variação na utilização das cores, ainda que o verde continue presente em pontos estratégicos.

A peroba rosa está presente em doze de quatorze cartazes, seja por meio de ilustração ou fotografia. Outros elementos, como a capela, os departamentos, o calçadão, entre outros, figuram em seis de quatorze cartazes. Dependendo da abordagem, estes elementos regionais podem não ser reconhecidos com toda sua carga simbólica, principalmente quando são apresentados em nível de detalhe, por se tratar de elementos de significado regional condicionados ao conhecimento das particularidades do campus e da comunidade universitária, conforme já citado na análise do cartaz de 2013. Entretanto, dependendo da abordagem, estes mesmos elementos podem fornecer ao público pistas sobre a cultura universitária, sobre suas raízes e sua essência, contribuindo para a disseminação de imagens regionais, como visto nos cartazes de 2012 e 2014.

Alguns autores exploraram abordagens mais ousadas, em que a inspiração e as referências pertencem a universos variados: literatura, games, filmes, artes, jogos, entre outros, evidenciando a característica multimídia encontrada neste tipo de profissional. 


\section{CONSIDERAC̣ÕES FINAIS}

O presente estudo registra uma importante atividade desenvolvida no Departamento de Design da UEL, que contribui para o desenvolvimento dos futuros profissionais da área, cujo trabalho repercute dentro e fora do ambiente acadêmico. Sendo o cartaz um produto de seu tempo, registra historicamente uma atividade que é desenvolvida há quatorze anos e que de fato representa a Universidade, contribuindo para a divulgação e promoção da marca UEL. Enquanto análise contribui para o desenvolvimento do design gráfico local respeitando as particularidades históricas e culturais da região.

\section{REFERÊNCIAS}

BERTOMEU, João V. C. Criação na redação publicitária. São Paulo: Mercado de Ideias, 2006.

BOTELHO, Beatriz. COPS divulga layout do Vestibular 2017. Agência UEL de Notícias, LONDRINA, 1 jul. 2016. Disponível em: <http://www. uel.br/com/agenciaueldenoticias/index.php?arq=ARQ_not\&FWS_ Ano_Edicao=1\&FWS_N_Edicao=1\&FWS_N_Texto=23098\&FWS_Cod_ Categoria=2>. Acesso em: 2 nov. 2016.

BRINGHURST, Robert. Elementos do estilo tipográfico (versão 4.0). 3. ed. São Paulo: Cosac Naify, 2015.

CEZAR, Juliano Carlos Plaça; MARCONDES, Martha Aparecida Santana (Org.). Uma universidade em evolução. Londrina: UEL, 2013. Disponível em: <http://www.uel.br/ proplan/portal/pages/arquivos/daai/uma_ universidade_em_evolucao.pdf>. Acesso em: 7 jan. 2016.

GOMES FILHO, João. Gestalt do objeto: sistema de leitura visual da forma. 9. ed. São Paulo: Escrituras, 2009.

HERSCHMANN, Micael Maiolino; PEGORARO, Everli; FERNANDES, Cíntia Sanmartin. Steampunk e retrofuturismo: reflexos de inquietações sociotemporais contemporâneas. CMC: Comunicação, Mídia e Consumo, São Paulo, Ano 10, n.28, p.209-228, Maio/ago. 2013.

HOLLIS, Richard. Design gráfico: uma história concisa. São Paulo: Martins Fontes, 2000.

LUPTON, Ellen. Pensar com tipos: guia para designers, escritores, editores e estudantes. 2. ed. São Paulo: Cosac Naify, 2013.

LUPTON, Ellen; PHILLIPS, Jennifer Cole. Novos fundamentos do Design. 3. ed. São Paulo: Cosac Naify, 2014.

MEGGS, Phillip B.; PURVIS, Alston W. História do Design Gráfico. 4. ed. 
São Paulo: Cosac Naify, 2009.

MOLES, Abraham. O cartaz. São Paulo: Ed. Perspectiva, 1974.

SANTAELLA, Lúcia. O que é Semiótica. São Paulo: Brasiliense, 1983.

SANTAELLA, Lúcia. Semiótica Aplicada. São Paulo: Pioneira Thomson Learning, 2005.

UEL. Coordenadoria de Processos Seletivos -COPS. Cartazes dos Vestibulares UEL desde 1991. Disponível em: <http://www.cops.uel.br/ vestibular/cartazes/>. Acesso em: 20 mar. 2015.

UEL. Coordenadoria de Processos Seletivos. Inscrições do Vestibular 2017 começam em 11 de agosto. Agência UEL de Notícias, LONDRINA, 21 jul. 2016a. Disponível em: <http://www.uel.br/com/agenciaueldenoticias/ index.php?arq=ARQ_not\&FWS_Ano_Edicao $=1 \& \mathrm{FWS} N$ _Edicao $=1 \& \mathrm{FWS}$ Cod_Categoria=2\&FWS_N_Texto=23229>. Acesso em: 10 fev. 2017.

UEL. Normas para uso da Marca-Símbolo. Disponível em: <http://www. uel.br/ marcasimbolo>. Acesso em: 3 jan. 2016.

WHEELER, Alina. Design de identidade da marca: guia essencial para toda a equipe de gestão de marcas. Bookman: Porto Alegre, 2012. 